\title{
Glutamine and Glutamate Supplementation Increases the Levels of These Amino Acids in the Milk of Pasture-fed Mares
}

\author{
Elizabeth Regina Rodrigues da Silva, Monica Miranda Hunka, \\ Helena Emília Cavalcanti da Costa Cordeiro Manso, \& Hélio Cordeiro Manso Filho
}

\begin{abstract}
Background: L-Glutamine (Gln), the most abundant free alpha amino acid in the body, plays a major role in the transport of nitrogen and carbon between tissues, and is an important source of respiratory energy for intestinal and immune system cells. Mares lose lean body mass during lactation, when plasma and milk Gln levels change significantly. However, supplementation with Gln combined with other amino acids may not alter equine plasma Gln levels. The work reported here was designed to test the hypothesis that supplementation with a mixture of glutamine and glutamate (AminoGut) alters blood and milk free glutamine and glutamate levels in pasture-fed lactating mares.

Materials, Methods \& Results: This study involved 31 multiparous Quarter Horse mares, which were divided into three groups immediately postpartum, as follows: G-CON ( $=19)$; G-50 g supplemented with $50 \mathrm{~g}$ of Gln + Glu plus $200 \mathrm{~g}$ of concentrate $(n=6)$; and G-100 g, supplemented with $100 \mathrm{~g}$ of Gln + Glu plus $200 \mathrm{~g}$ of concentrate $(n=6)$. Blood and milk samples were collected on the day of parturition prior to supplementation, and monthly until weaning. The milk samples were used to analyze the Gln, Glu composition and levels, while the blood samples were used for further analysis of blood biomarkers. The results were analyzed by ANOVA and by Tukey's test and the $P$ value was set at $5 \%$. The G-CON group showed a significant reduction of 11-35\% in the mean blood glutamine levels from the first month postpartum and throughout lactation. In contrast, blood glutamine levels in groups G-50 g and G-100 g did not change significantly from parturition through 5 months of lactation. The supplemented groups showed no significant differences in blood variables such as protein, albumin, urea, creatinine, cholesterol, triglycerides and minerals. Free glutamine levels in milk did not change from parturition through the end of lactation in the G-CON group, but groups G-50 g and the G-100 g showed a marked rise in milk glutamine levels throughout the first three months of lactation $(\sim 3 \mathrm{x})$, which remained high $(\sim 2 \mathrm{x})$ until the foals were weaned $(P>0.05)$.

Discussion: The results of this study indicate that Gln + Glu supplementation successfully increased Gln levels in mare milk in the first three months of lactation, and Glu levels in G-100 g in the first four months, without affecting the levels of these amino acids in the animals' blood, which remained similar to data obtained at parturition. In fact, the Gln levels in both supplemented groups exceeded $1,000 \mathrm{mmol} / \mathrm{mL}$ throughout lactation, unlike those of the control group and of the samples obtained at parturition. Moreover, supplementation did not produce significant changes in blood biomarkers, including those pertaining to protein metabolism (urea, creatinine, uric acid, albumin and total proteins), indicating that the product used for supplementation did not interfere in these biomarkers, which remained within the normal physiological variations for the species. It was concluded that daily dietary supplementation with $50 \mathrm{~g}$ of a mixture of glutamine and glutamate produced an effect similar to supplementation with $100 \mathrm{~g} /$ day. Both supplementation protocols succeeded in raising glutamine levels in mare milk in the first three months of lactation, without interfering in blood biomarkers or milk composition. In view of the cost of the product, we recommend that the daily diet of mares during lactation be supplemented with $50 \mathrm{~g}$ of a mixture of Gln + Glu in order to produce the desired nutritional effects.
\end{abstract}

Keywords: amino acids, catabolism, equine nutrition, foals, lactation. 


\section{INTRODUCTION}

L-Glutamine (Gln), the most abundant free alpha amino acid in the body, plays a major role in the transport of nitrogen and carbon between tissues, and is an important source of respiratory energy for intestinal and immune system cells. The large pool of glutamine in the body is produced by skeletal muscle, liver, adipose tissue and mammary glands $[14,16]$. During catabolic states, the glutamine turnover increases in these tissues, often leading to lower glutamine levels. This has been observed in horses subjected to different exercise intensities or after illness [5,19,28,31], indicating the importance of glutamine supplementation to correct the balance in glutamine metabolism in some groups of horses.

Mares lose lean body mass during lactation, when plasma and milk Gln levels undergo significant modifications. However supplementation with Gln combined with other amino acids may not alter the plasma Gln levels of horses $[6,11]$. This is not surprising, since dietary glutamine is almost completely metabolized by the small intestine of horses and does not enter the blood circulatory system [2]. To date there are no studies of the effects of glutamine supplementation in the lactating mares. Evidence from pig studies shows that maternal supplemental glutamine and glutamate can attenuate muscle glutamine concentrations and increase the free glutamine content of milk $[1,11]$. The work reported here was designed to test the hypothesis that supplementation with a mixture of glutamine and glutamate (AminoGut) alters blood and milk free glutamine and glutamate levels in pasture-fed lactating mares.

\section{MATERIALS AND METHODS}

\section{Animals}

This study involved 31 four to twelve-year-old multiparous Quarter Horse mares. The mares were kept on good quality pastures of Massai grass (Panicum maximum cv. Massai), with no concentrate supplementation but free access to water and mineral salt licks throughout their gestation and lactation period. All the mares lived on the same farm $\left(07^{\circ} 5^{\prime} 1^{\prime \prime} \mathrm{S}, 35^{\circ} 19^{\prime} 11^{\prime \prime} \mathrm{W}\right.$, Lagoa do Carro, PE, Brazil) and the foaling season occurred between September and November.

\section{Supplementation protocol}

The mares were divided into three groups immediately postpartum: group G-CON, or control group, which did not receive Gln + Glu supplementation but received $200 \mathrm{~g}$ of concentrate $(\mathrm{n}=19)$; group $\mathrm{G}-50 \mathrm{~g}$, supplemented with $50 \mathrm{~g}$ of Gln + Glu plus $200 \mathrm{~g}$ of concentrate $(n=6)$; and group G-100 g, supplemented with $100 \mathrm{~g}$ of Gln + Glu plus $200 \mathrm{~g}$ of concentrate $(\mathrm{n}=$ 6). The mixture of Gln + Glu contained a minimum of $10 \%$ L-Glutamine and 10\% L-Glutamate, AminoGut ${ }^{1}$, and the concentrate provided $13 \% \mathrm{CP}, 3 \% \mathrm{EE}$, and 3,030 $\mathrm{kcal} / \mathrm{kg}$ DE, Proequi 13 Laminados, Guabi². The mares received dietary supplementation starting on the first day postpartum and ending in the fifth month, when the foals were weaned. The foals did not receive supplementation.

\section{Collection and analysis of milk and blood samples}

Blood and milk samples were collected on the day of parturition, $6 \mathrm{~h}$ after birth, before supplementation started, and once a month in the first to the fifth month postpartum. To collect the milk samples, the foals were separated from their mothers for $30 \mathrm{~min}$; the mares were then milked manually without oxytocin. Milk samples were collected from the two teats of each animal, mixed, and divided into two aliquots. One aliquot $(30 \mathrm{~mL})$ was placed in bottles containing Bronopol (antimicrobial) and refrigerated for later use in the automated determination of milk composition and somatic cell counting, Bentley $2000^{3}$. The second aliquot was transferred to tubes containing an equal volume of $10 \%$ perchloric acid (PCA) for deproteinization, and the supernatant was neutralized with $\mathrm{KOH}$ before the enzymatic analysis of Gln and Glu concentrations [13].

Immediately after milking, blood samples were drawn into heparin-coated tubes by jugular venipuncture from the animals fasted overnight. To obtain plasma for further analysis of blood biomarkers (urea, creatinine, uric acid, total protein, albumin, total cholesterol, triglycerides, calcium, phosphorus, magnesium and iron), one of the blood samples was centrifuged using a semi-automatic biochemical analyzer, Doles D-250 and a commercial biochemical kit Doles ${ }^{4}$. A second blood sample was deproteinized with PCA and analyzed for Gln and Glu concentrations, as was done with the milk samples.

\section{Statistical analysis}

The results were analyzed by one-way ANOVA and by Tukey's test to compare all the groups. In both cases, the $P$ value was set at $5 \%$. Samples obtained from all three groups upon parturition, prior to supplementation, were pooled for statistical analysis, using the SigmaStat 13.0 program, and the results of these analyses are expressed as mean and average standard error. 


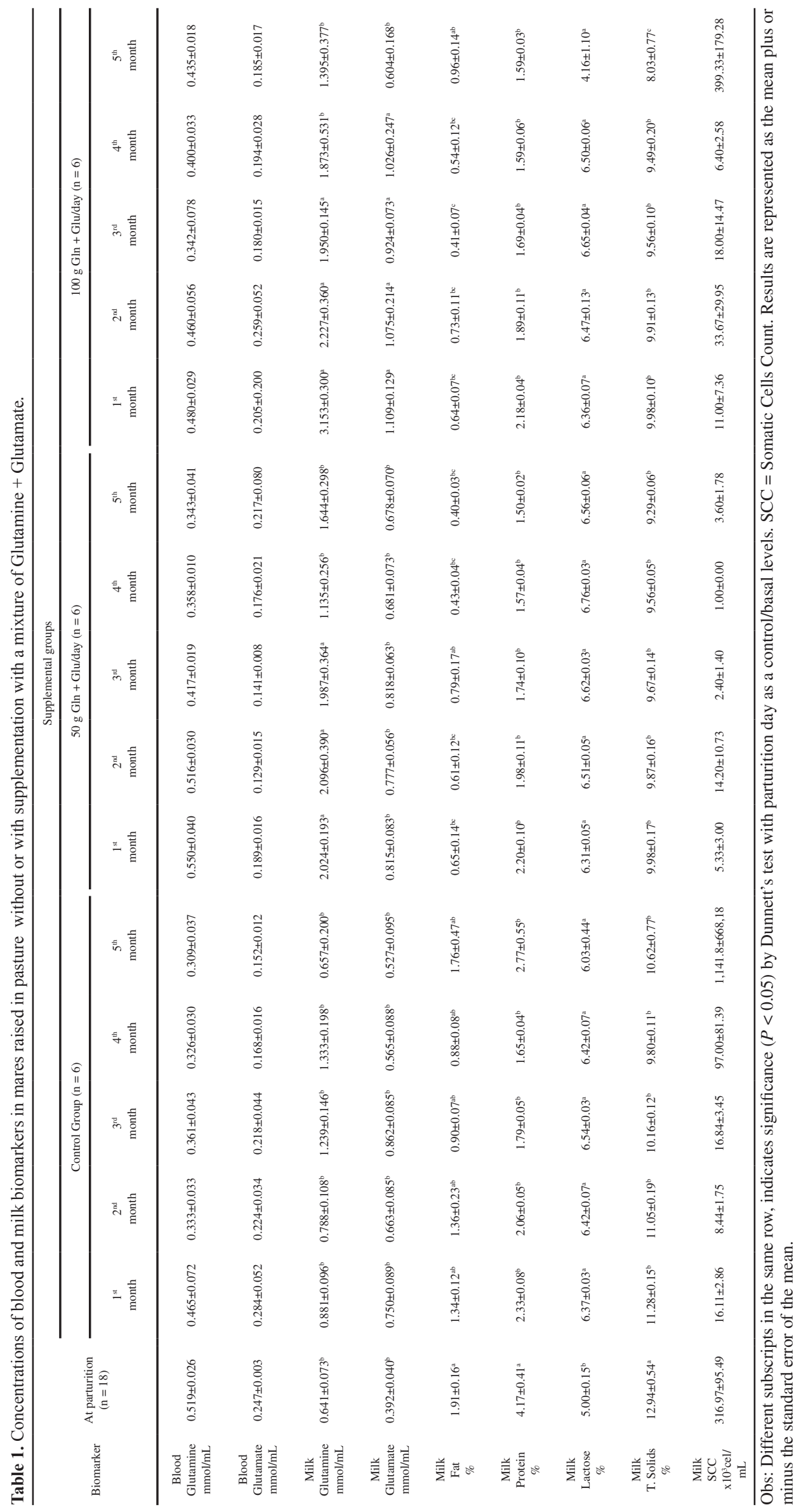




\section{RESULTS}

The G-CON group showed a significant reduction of $11-35 \%$ in the mean blood glutamine levels from the first month after birth and throughout lactation (Table 1). In contrast, changes in blood glutamine levels in the G-50 g and the G-100 g groups from parturition through 5 months of lactation were negligible. Blood glutamate levels, and the total blood glutamine plus glutamate concentrations, did not change significantly in any group over time. No significant differences were found in blood variables such as protein, albumin, urea, creatinine, cholesterol, triglycerides and minerals in the two supplemented groups over time (Table 2).

The free glutamine content in milk did not change from parturition through the end of lactation in G-CON, but showed a marked increase in groups G-50 $\mathrm{g}$ and $\mathrm{G}-100 \mathrm{~g}$ throughout the first three months of lactation $(\sim 3 \mathrm{x})$ remaining high $(\sim 2 \mathrm{x})$ until the foals were weaned $(P>0.05)$. Milk glutamate did not change in group G-CON throughout lactation, but increased slightly in group G-50 g in the first month of lactation, while group G-100 g showed a similar increase from the first to the fourth month postpartum. Similarly, the glutamine plus glutamate concentration was unchanged throughout lactation in G-CON, but rose significantly in G-50 $\mathrm{g}$ and G-100 $\mathrm{g}$ during the first 3-4 months of lactation ( 2,5x). Milk fat content tended to show a significant drop as lactation proceeded, but supplementation did not lead to major differences. Similarly, milk protein content and milk total solids content were significantly lower during lactation when compared to the sample collected upon parturition, but were unaffected by supplementation. Milk somatic cell count (SCC) showed no significant differences in any group or at any time.

\section{DISCUSSION}

The results of this work showed that Gln + Glu supplementation increased the Gln levels in mares' milk in the first three months of lactation, and the Glu levels in G-100 $\mathrm{g}$ in the first four months, without changing the levels of these amino acids in the animals' blood, which remained similar to the levels recorded at parturition. Indeed, the levels of Gln in both supplemented groups exceeded 1,000 $\mathrm{mmol} / \mathrm{mL}$ throughout lactation, unlike those in the control group and in the samples collected at parturition. Moreover, supplementation did not produce significant changes in blood biomarkers, including those linked to protein metabolism (urea, creatinine, uric acid, albumin and total proteins), demonstrating that the product used for supplementation did not interfere in these biomarkers, which remained within the physiological variations for the species [3]. Therefore, it can be stated that a mixture of Gln and Glu, when used as a dietary supplement for lactating mares, provides greater availability of these amino acids for newborn foals during the critical phase of adaptation to postnatal life, thus favoring their development.

Glutamine can be considered a functional amino acid because it controls several metabolic pathways, improving health, survival, growth, development, lactation and reproduction [32], and increased Gln levels in blood, muscle or milk may be important for maintaining the health of different groups of animals. For example, in piglets, Gln supplementation increased the expression of genes responsible for cell growth and the removal of oxidants by about $120 \%$ [29]. Moreover, Gln is actively synthesized by the mammary glands, which express Glutamine Synthetase [8,13]. Also, up to $50 \%$ of Gln and probably all of Glu contained in milk are synthesized in the mammary glands [26], but the cells responsible for this synthesis have not yet been definitively identified. Probably, mammary epithelial cells and mammary adiposities are jointly responsible for the significant increase in Gln in milk [30].

In horses, it has been demonstrated that foals are born with high Gln levels in skeletal muscle, and that this level declines by $\sim 55 \%$ at around the third month after birth, becoming similar to that of young adults in this tissue, whereas blood Gln levels increase by $\sim 35 \%$ [15]. This substantial increase in blood Gln is due to both endogenous and exogenous supply produced by the mare's mammary glands, which produce milk rich in Gln early in lactation [14]. Also, the mare's mammary glands express three-fold higher glutamine synthetase than the level detected in horse gluteal muscle and similar to that in the kidney, confirming the importance of this tissue to Gln synthesis in this species [13]. This large amount of Gln in mare's milk contributes not only to early intestinal development, supporting a large increase in food/milk intake, but also to deliver carbon and nitrogen for other metabolic functions. It is also important to keep in mind that Gln may contribute to produce Glu and could affect the level of food intake by suckling foals and other mammals. This amino acid is associated with a taste stimulus (umami taste) and may play a role in promoting satiety in animals [20]. 


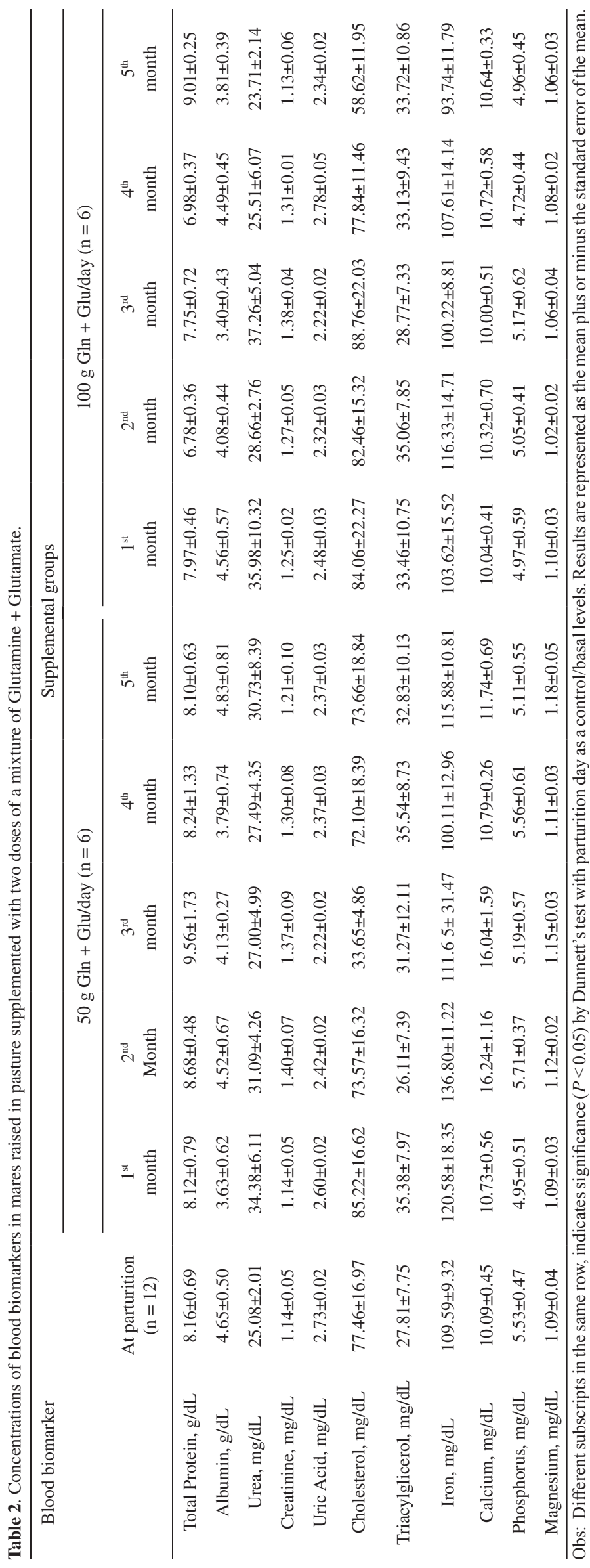


The high Gln levels in milk observed among equines also occurs in other domestic species, for which lactation is an important phase of breeding $[1,7,9,11]$. In dairy cows not receiving dietary Gln supplementation, plasma and muscle Gln levels decrease while milk Gln levels remain unchanged [16]. It should also be kept in mind that muscle Gln levels decline in lactating mares that do not receive supplemental Gln [14], similar to what occurs in dairy cows and pigs. In the latter species, supplementation contributes to increase milk Gln without decreasing muscle Gln [11].

Therefore, Gln + Glu supplementation may be an important nutritional resource for lactating mares, as has been proposed for dairy cows and pigs $[1,11,16]$, possibly limiting muscle catabolism and helping them to maintain fat-free body mass. This is important to regulate the female reproductive cycle [27], especially that of pasture-fed females, since the quality and quantity of nutrients in grass may vary throughout the year and animals may use their protein and fat stores to support gestation and lactation.

In this study, the two Gln supplemented groups showed no change in plasma Gln levels, but the Gln levels found in these groups during five months of lactation were at about the physiological concentration $(0.500-0.800 \mathrm{mmol} / \mathrm{mL})[12,14,19,22]$. In contrast, the plasma Gln levels in G-CON decreased significantly after four months of lactation ( $35 \%)$, a finding similar to that observed in lactating Standardbred mares fed with $10 \%$ higher supplemental dietary Gln than that recommended by the National Research Council (NRC) [18] for this category [14].

Plasma Gln and Glu levels vary during different phases of a horse's life. In newborn foals, plasma Gln levels increase dramatically ( 50\%) a week after birth [15], while in athletic horses these levels decrease after exercise [19,28]. However, supplemental dietary Gln has presented conflicting results in horses. Dietary supplementation programs vary significantly and Gln is consumed by enterocytes in equines, making it difficult to interpret the results, thereby contributing to increase the difficulties in understanding the physiological and metabolic effects of Gln and Glu supplementation.

Many researchers have reported the effects of enteral administration and of different dosages or duration of Gln supplementation in healthy horses. It has been shown that the diet can affect glutamine levels in healthy horses, but 10 days of oral supplementation with Gln did not cause changes in plasma Gln levels $[6,19]$. The authors of the latter study showed that plasma Gln levels changed in the postprandial period ( 1.5 hour) after oral supplementation $(30-60 \mathrm{mg} / \mathrm{Kg}$ ), but returned to pretest levels after three hours. Another study demonstrated that dietary supplementation of athletic horses with a mixture of Gln + Glu (50 g/day) did not modify plasma Gln levels but significantly reduced plasma Glu levels [12].

Blood biomarkers in supplemented mares were also analyzed to ensure that there were no changes indicating homeostatic imbalances or impairments caused by supplementation. The results indicated that these supplemented mares were not affected by lactation or by the level of supplementation (50 g x $100 \mathrm{~g}$ ), since none of the analyzed biomarkers showed any difference $(\mathrm{P}<$ $0.05)$, and all of them were within published reference values for equines $[3,17,25]$. However, in athletic horses, 28 days of dietary supplementation with the Gln + Glu mixture (50 g/day) resulted in a slight increase in protein biomarkers (TP, albumin, creatinine, urea, uric acid) and total cholesterol, although these concentrations are also subject to physiological variations [12]. In contrast, horses fed at maintenance level supplemented with Gln and yeasts did not show an increase in these protein and fat biomarkers [10], and oral supplementation with Gln in different doses (30 or $60 \mathrm{mg} / \mathrm{kg}$ ) did not affect some protein biomarkers in horses [6]. Those studies confirm how Gln and Glu supplementation may lead to different results, but further studies about the correlation between these amino acids and changes in blood and/or milk in horses are needed to better utilize their nutritional and metabolic potential.

Mares receiving Gln + Glu supplementation showed an unexpected effect, i.e., it was found that milk fat levels in G-50 g decreased $(P<0.05)$, which was not the case in the control group during early and late lactation, and in G-100 g during late lactation. In female swine, it has been shown that Gln + Glu supplementation is also associated with the lipogenic effect, increasing milk fat content without modifying milk protein and lactose content [1]. Apparently there is a difference between the species, but mares depend on fodder for milk production, whereas sows depend on the concentrate; another major difference is the duration of lactation. In mares, the milk fat content often decreases as lactation progresses [4,21,23,24], as was observed in the G-50 g group of this study. An analysis of other mare milk constituents indicated that the concentration of protein, lactose and solids 
concentrations did not differ among the groups and that they followed the typical pattern for the species, and did not appear to be related to Gln + Glu supplementation.

\section{CONCLUSIONS}

It was concluded that daily dietary supplementation with $50 \mathrm{~g}$ of a mixture of glutamine and glutamate produced an effect similar to that of supplementation with $100 \mathrm{~g} /$ day. Both supplementation protocols effectively increased glutamine levels in mares' milk in the first three months of lactation, without interfering in blood biomarkers or milk composition. In view of the cost of the product, it is recommended that mares are fed a daily supplement mixture of $50 \mathrm{~g}$ of Gln + Glu during lactation to enhance their performance.
MANUFACTURERS

${ }^{1}$ Ajinomoto do Brasil. São Paulo, SP, Brazil.

${ }^{2}$ Guabi Nutrição Animal. Campinas, SP, Brazil.

${ }^{3}$ Bentley Instruments Inc. Chaska, MN, USA.

${ }^{4}$ Doles Reagentes e Equipamentos para Laboratório, Goiânia, GO, Brazil.

Acknowledgements. The authors gratefully acknowledge the financial support of this work by CNPq, Brazil's National Council for Scientific and Technological Development, and the practical support provided by Guabi Nutrição Animal, Ajinomoto Brasil, and Fazenda Uberaba (Lagoa do Carro-PE, Brazil).

Ethical approval. All the procedures employed in this study were approved by the Animal Research Ethics Committee of the Federal Rural University of Pernambuco (Number: 018/2014).

Declaration of interest. The authors report no conflicts of interest. The authors alone are responsible for the content and writing of paper.

\section{REFERENCES}

1 Aquino R.S., Dutra Júnior W.M., Manso H.E.C.C., Manso Filho H.C., Kutschenko M., Nogueira E. \& Watford M. 2014. Glutamine and Glutamate (AminoGut) Supplementation Influences Sow Colostrum and Mature Milk Composition. Livestock Science. 169: 112-117.

2 Duckworth D.H., Madison J.B., Calderwood-Mays M. \& Souba W.W. 1992. Arteriovenous Differences for Glutamine in the Equine Gastrointestinal Tract. American Journal of Veterinary Research. 53(10): 1864-1867.

3 Ferreira L.M.C., Hunka M.M., Silva E.R.R., Melo S.K.M., Melo A.C.C., Trindade K.L.G., Oliveira V.T.B.M., Manso H.E.C.C.C. \& Manso Filho H.C. 2016. Hematological and Biochemical Values in Brazilian Four-Beat Gaited Horses. Comparative Clinical Pathology. 25(6): 259-263.

4 Gibbs P.G., Potter G.D., Blake R.W. \& Mcmullan W.C. 1982. Milk Production of Quarter Horse Mares During 150 Days of Lactation. Journal of Animal Science. 54 (3): 496-499.

5 Hackl S., van den Hoven R., Zickl M., Spona J. \& Zentek J. 2009. The Effects of Short Intensive Exercise on Plasma Free Amino Acids in Standardbred Trotters. Journal of Animal Physiology and Animal Nutrition. 93(2): 165-173.

6 Harris R.C., Harris P., Routledge N.B.H., Naylor J. \& Wilson A.M. 2006. Plasma Glutamine Concentrations in the Horse Following Feeding and Oral Glutamine Supplementation. Equine Veterinary Journal. 38(36): 637-642 .

7 Kul M., Vurucu S., Demirkaya E., Tunc T., Aydinoz S., Meral C., Kesik V. \& Alpay F. 2009. Enteral Glutamine and/or Arginine Supplementation Have Favorable Effects on Oxidative Stress Parameters in Neonatal Rat Intestine. Journal of Pediatric Gastroenterology and Nutrition. 49(1): 85-89.

8 Lei J., Feng D., Zhang Y., Zhao F.Q., Wu Z., San Gabriel A., Fukishima Y., Uneyama H. \& Wu G. 2012. Nutritional and Regulatory Role of Branched-Chain Amino Acids in Lactation. Frontiers in Bioscience. 17: 2725-2739.

9 Lima D.S.C., Maia L.M.S., Barboza E.A., Duarte R.A., Souza L.S. \& Guedes R.C.A. 2009. L- Glutamine Supplementation During the Lactation Period Facilitates Cortical Spreading Depression in Well-Nourished and EarlyMalnourished Rats. Life Sciences. 85(5-6): 241-247.

10 Lindinger M.I. \& Anderson S.C. 2014. Seventy Day Safety Assessment of an Orally Ingested, L-Glutamine-Containing Oat and Yeast Supplement for Horses. Regulatory Toxicology and Pharmacology. 70(1): 304-311.

11 Manso H.E., Manso Filho H.C., De Carvalho L.E., Kutschenko M., Nogueira E.T. \& Watford M. 2012. Glutamine and Glutamate Supplementation Raise Milk Glutamine Concentrations in Lactating Gilts. Journal of Animal Science and Biotechnology. 3(1): 1-7.

12 Manso H.E.C.C.C., Silva C.J.F.L., Barbosa B.L., Vasconcelos J.L.A. \& Manso Filho H.C. 2015. Efeitos da Suplementação com Glutamina e Glutamato sobre os Índices Hematimétricos e Biomarcadores Sanguíneos de Equinos. Acta Scientiae Veterinariae. 43: 1-7. 
13 Manso Filho H.C., Costa H.E.C., Wang Y., McKeever K. H. \& Watford M. 2008. Distribution of Glutamine Synthetase and an Inverse Relationship Between Glutamine Synthetase Expression and Intramuscular Glutamine Concentration in the Horse. Comparative Biochemistry and Physiology. Part B. 150: 326-330.

14 Manso Filho H.C., Mckeever K. H., Gordon M.E., Costa H.E.C., Lagakos W.S. \& Watford M. 2008. Changes in Glutamine Metabolism Indicate a Mild Catabolic State in the Trasition Mare. Journal of Animal Science. 86: 34243431.

15 Manso Filho H.C., McKeever K.H., Gordon M.E., Manso H.E., Lagakos W.S., Wu G. \& Watford M. 2009. Developmental Changes in the Concentrations of Glutamine and Other Amino Acids in Plasma and Skeletal Muscle of the Standardbred Foal. Journal of Animal Science. 87(8): 2528-2535.

16 Meijer G.A.L., Van Der Meulen J., Bakker J.G.M., Van Der Koelen C.J. \& Van Vuuren A.M. 1995. Free Amino Acids in Plasma and Muscle of High Yielding Dairy Cows in Early Lactation. Journal of Dairy Science. 78(5): 11311141.

17 Melo S.K.M., Lira L.B., Almeida T.L.A.C., Rêgo E.W., Manso H.E.C.C.C. \& Manso Filho H.C. 2013. Índices Hematimétricos e Bioquímica Sanguínea no Cavalo de Cavalgada em Condições Tropicais. Ciência Animal Brasileira. 14 (2): 208-215.

18 National Research Council - NRC. 2007. Nutrients Requirements of Horses. 6th edn. Washington D.C.: NRC, 341p.

19 Routledge N.B., Harris R.C., Harris P.A., Naylor J.R. \& Roberts C.A. 1999. Plasma Glutamine Status in the Equine at Rest, During Exercise and Following Viral Challenge. Equine Veterinary Journal. 30: 612-616.

20 San Gabriel A. \& Uneyama H. 2013. Amino Acid Sensing in the Gastrointestinal Tract. Amino Acids. 45: 451-461.

21 Santos E.M. \& Zanine A.M. 2006. Lactação em Éguas. Revista Portuguesa de Ciências Veterinárias. 101(557-558): $17-23$.

22 Silver M., Fowden A.L., Taylor P.M., Knox J. \& Hill C.M. 1994. Blood Amino Acids in the Pregnant Mare and the Fetus: The Effects of Maternal Fasting and Intrafetal Insulin. Experimental Physiology. 79(3): 423-433.

23 Smolders E.A.A., Van Der Veen N.G. \& Van Polanen A. 1990. Composition of Horse Milk During the Suckling Period. Livestock Production Science. 25(1-2): 163-171.

24 Solaroli G., Pagliarini E. \& Peri C. 1993. Composition and Nutritional Quality of Mare's Milk. Italian Journal of Food Science. 5(1): 3-10.

25 Soncin M.R.S., Furtado C.E., Silva A.A., Rigolon L.P., Cavalieri F.L.B. \& Moraes G.V. 2009. Digestibilidade Aparente, Crescimento Folicular e Concentração de Metabólitos Sanguíneos de Éguas Recebendo Concentrado com Semente de Linhaça Integral (Linum Usitatissimum L.). Acta Scientiarum Animal Science. 31(2): 191-197.

26 Trottier N.L., Shipley C.F. \& Easter R.A. 1997. Plasma Amino Acid Uptake by the Mammary Gland of the Lactating Sow. Journal of Animal Science. 75(5): 1266-1278.

27 Vailati-Riboni M., Meier S., Burke C.R., Kayy J.K., Mitchell M.D., Walker C.G., Crookenden M.A., Heiser A., Rodriguez-Zas S.L., Roche J.R. \& Loor J.J. 2016. Prepartum Body Condition Score and Plane of Nutrition Affect the Hepatic Transcriptome During the Transition Period in Grazing Dairy Cows. BMC Genomics, 17(1): 854

28 Wanderley E.K., Manso Filho H.C., Manso H.E.C.C.C., Santiago T.A. \& Mckeever K.H. 2010. Metabolic Changes in Four Beat Gaited Horses After Field Marcha Simulation. Equine Veterinary Journal. 42(38): 105-109.

29 Wang J., Chen L., Li P., Li X., Zhou H., Wang F., Li D., Yin Y. \& Wu G. 2008. Gene Expression Is Altered in Piglet Small Intestine by Weaning and Dietary Glutamine Supplementation. The Journal of Nutrition. 138(6): 1025-1032.

30 Wang Y. \& Watford M. 2007. Glutamine, Insulin and Glucocorticoids Regulate Glutamine Synthetase Expression in C2C12 Myotubes, Hep G2 Hepatoma Cells and 3T3 L1 Adipocytes. Biochimica et Biophysica Acta - General Subjects. 1770(4): 594-600.

31 Westermann C.M., Dorland L., Wijnberg I.D., de Sain-van der Velden M.G., van Breda E., Barneveld A., de Graaf-Roelfsema E., Keizer H.A. \& van der Kolk J.H. 2011. Amino acid Profile During Exercise and Training in Standardbreds. Research in Veterinary Science. 91(1): 144-149.

32 Wu G. 2010. Functional Amino Acids in Growth, Reproduction, and Health. Advances in Nutrition. 1(1) 31-37. 